12th International Conference on Plasma Surface Engineering

September 13-17, 2010

Garmisch-Partenkirchen. Germany

\title{
EFFECT OF OXYGEN/FUEL RATIO ON THE IN-FLIGHT PARTICLE PARAMETERS AND PROPERTIES OF HVOF WC-CoCr COATINGS
}

\author{
J.A. Picas, M. Punset, M.T. Baile, E. Martín, A. Forn
}

Light Alloys and Surface Treatments Design Centre (CDAL). Universitat Politècnica de Catalunya, 08800 Vilanova i la Geltrú, Spain. josep.picas@upc.edu

\begin{abstract}
High Velocity Oxy-Fuel (HVOF) spray techniques can produce high performance alloy and cermet coatings for applications that require wear resistant surfaces. In HVOF spraying heat is produced by burning mixtures of oxygen and fuel, mainly hydrogen, kerosene, propane, propylene, natural gas or acetylene. In these processes, the particle velocity and temperature determine the resultant coating properties and in many cases enables a better understanding of the process.

The aim of this study is to investigate influences of different oxygen/fuel ratios on velocity and temperature of flying particles as well as properties of the HVOF thermal sprayed WC-CoCr coatings. In this work the feedstock powders were thermally sprayed by two different variants of the high velocity oxy-fuel process, in which the fuels were hydrogen and kerosene.

Particle parameters were recorded just prior to impact on the substrate using in-flight particle diagnostic tool Accuraspray-g3 ${ }^{\circledR}$. Detailed correlation of particle parameters and the coating properties is evaluated in order to deduce particle parameter ranges providing coatings with optimum properties.
\end{abstract}

Keywords: HVOF thermal spray; In-flight particle parameters; WC-CoCr; Coatings; Microstructure; Hardness. 